\title{
Selvmordsforekomst og selvmordsfare ved Aspergers syndrom
}

\author{
Ved Christian Hjort
}

\begin{abstract}
I artikkelen drøftes forekomst, forebygging og vurdering av selvmordsatferd ved Aspergers syndrom. Den forskningsbaserte kunnskapen på området er begrenset. Kunnskap om Aspergers syndrom og relaterte tilstander er viktig både i barnehage- og skolesystem og i sosial-og helsevesen. Forskning på selvmordsforekomst og selvmordsatferd ved autismespektrumlidelser bør prioriteres.
\end{abstract}

\section{Innledning}

Det er ikke gjennomført systematiske studier av suicidal atferd ved Aspergers syndrom (AS). Det lille som finnes av forskning på området, er basert på små og kliniske populasjoner.

Artikkelen er basert på litteraturs $\varnothing \mathrm{k}$ (søkeord Asperger syndrome, autism, high functioning autism, pervasive developmental disorders (PDD), autism spectrum disorders (ASD) i kombinasjon med suicide, suicidal behaviour, self destructive behaviour, depression, psychosis, personality disorder, psychiatric disorder og comorbidity) og på litteraturreferanser i relevante artikler. Artikkelen bygger også på kommunikasjon med noen ledende forskere på autismeområdet samt på egne erfaringer.

\section{Aspergers syndrom}

Betegnelsen Aspergers syndrom ble introdusert av Lorna Wing i en banebrytende artikkel fra 1981 (Wing, 1981). Med utgangspunkt i en artikkel av Hans Asperger fra 1944 der han beskrev barn med det han kalte "autistische Psychopatie" (Asperger, 1944), beskrev hun 34 egne AS-pasienter. Siden har betegnelsen Aspergers syndrom (AS) gradvis vunnet hevd. I ICD-10 er syndromet klassifisert under de gjennomgripende utviklingsforstyrrelsene (PDD). I litteraturen brukes i økende grad betegnelsen autismespektrumforstyrrelser (autism spectrum disorders, ASD) i stedet for PDD.

Mennesker med AS har vansker med gjensidighet i sosial samhandling, vansker med sosial kommunikasjon (blant annet pragmatiske språkvansker og vansker med forståelse av kroppsspråk) samt en utpreget tendens til stereotype interesse- og atferdsmønstre (Hjort, 1994). Vanskene fører ofte til tilpasningsvansker, ensomhet og ikke sjelden til utst $\varnothing$ tning og mobbing. Barn med AS er vanligvis lite oppmerksomme på at de fungerer forskjellig fra jevnaldrende. Fra prepuberteten ses hos mange en $\varnothing$ kende bevissthet om annerledeshet. I samme alder får mange skolevansker fordi kravene til abstraksjonsevne $\varnothing$ ker. Spriket mellom $\varnothing$ nsket om inkludering og den faktiske ekskluderingen de fleste opplever, fører hos mange til depressiv symptomatologi og hos noen til tanker/ytringer om selvmord. Særlig i de ikke helt sjeldne tilfellene hvor unge med AS utsettes for alvorlig mobbing, vil risikoen for selvmordshandlinger $\varnothing$ ke.

Mange med AS har spesielle talenter som kan gjøre at de innenfor sine interesseområder kan utvikle eksepsjonelt gode ferdigheter.

\section{Komorbide lidelser som kan påvirke suicidrisiko}

Komorbide psykiske lidelser som kan være forbundet med $\varnothing \mathrm{kt}$ suicidrisiko er vanlig ved AS (Hjort, 2005).

Det er i en rekke unders $\varnothing$ kelser påvist $\varnothing \mathrm{kt}$ forekomst av affektive lidelser (Lainhart, 1999; Howlin, 2000; Ghaziuddin et al., 2002; Stahlberg, 2004; Stewart et al., 2006). Depresjon kan vise seg ved synlig nedstemthet, men ofte er de tydeligste symptomene forverring av "autismesymptomer" som repetitiv atferd, tvangshandlinger, tilbaketrekning, $s \varnothing v n-$ og appetittforandringer, selvskading eller aggresjon. Komorbid bipolar lidelse kan vise seg gjennom sykliske svingninger i aktivitet og atferdsendringer med affektivt preg (Frazier, 2002). Komorbid affektiv lidelse $\varnothing$ ker sannsynligvis suicidrisikoen ved AS betydelig. Symptombildet ved flere personlighetsforstyrrelser kan minne sterkt om AS.

Særlig gjelder dette schizoid personlighetsforstyrrelse og tvangspreget personlighetsforstyrrelse, men også emosjonelt ustabil personlighetsforstyrrelse av impulsiv type kan ha overlappende symptomer (Pelletier, 1998; Hjort, 2005).

Også hyperkinetiske lidelser og Tourettes syndrom, som kan gi $\varnothing \mathrm{kt}$ risiko for impulsive selvmordsfors $\varnothing \mathrm{k}$, forekommer hyppigere ved autismespektrumlidelser (Baron-Cohen et al., 1999; Kadesjø \& Gillberg, 2000; Goldstein \& Schwebach, 2004).

Psykotisk dekompensering under stress er ikke uvanlig ved AS (Tantam, 2003;
Hjort, 2005). Noen unders $\varnothing$ kelser tyder på $\varnothing \mathrm{kt}$ risiko for schizofreniutvikling (Wolff \& McGuire, 1995; Sturm et al., 2004; Stahlberg et al., 2004), mens andre taler mot en slik sammenheng (Volkmar \& Cohen, 1991; Kobayashi \& Murata, 1998; Howlin, 2000; Tantam, 2003).

Komorbide psykiske lidelser overses lett hos mennesker med AS fordi de psykiske symptomene oppfattes som kognitive karakteristika ved syndromet (Jopp \& Keys, 2001). Denne såkalte "diagnostiske overskyggingen" kan føre til underbehandling av depresjoner og andre lidelser og dermed til $\varnothing \mathrm{kt}$ risiko for selvmordshandlinger.

\section{Forskning om suicidalitet ved AS}

I Wings klinikkbaserte unders $\varnothing$ kelse av 34 pasienter med AS hadde én snakket om og én forsøkt suicid (Wing, 1981). I en etterunders $\varnothing$ kelse av en klinisk populasjon av pasienter med "schizoid personlighet", som forfatterne argumenterer for at oppfylte diagnosekriterier for AS, hadde 10 av 17 kvinner og 6 av 32 menn suicidal atferd (Wolff \& McGuire, 1995). I en st $\varnothing$ rre gruppe av schizoide pasienter fant de samme forfatterne at 3 av 33 kvinner og 3 av 115 menn hadde suicidert.

I en reviewbasert leder i "Crisis" konkluderte Fitzgerald (2007) med at suicidrisikoen ved AS er "mye høyere enn tidligere antatt". Basert på ovennevnte artikkel av Wolff og McGuire estimerte han en 16-dobling av selvmordshyppigheten ved 27-årsalder.

I en dansk klinikkbasert etterunders $\varnothing \mathrm{k}$ else av 18 pasienter med ASD (herav 9 med AS) med 30 års oppfølgingstid fant man ingen suicid (Larsen \& Mouridsen, 1997).

En japansk undersøkelse av en klinisk populasjon bestående av 180 ASD-pasienter mellom 18 og 33 år viste at selvmordstanker forekom i noen grad hos seks og i høy grad hos én av deltagerne (Kobayashi \& Murata, 1998). 


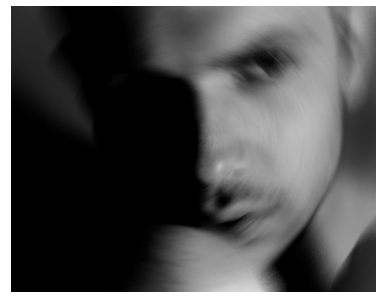

Hardan og Sahl gjennomførte en klinikkbasert undersøkelse av 233 barn og unge med utviklingsforstyrrelse og komorbid psykisk lidelse. 36 av pasientene hadde infantil autisme og 27 uspesifisert PDD. Tre i autismegruppen og fire i PDDgruppen hadde suicidal atferd (Hardan \& Sahl, 1999). Da forekomsten av selvmordsatferd var betydelig høyere hos pasienter uten ASD-problematikk, konkluderte man med at infantil autisme/ PDD beskytter mot suicidalitet.

I en unders $\varnothing$ kelse av 10 unge med AS som ble utsatt for mobbing, hadde $50 \%$ klinisk signifikant nivå av selvmordstanker (Shtayermman, 2007). Unders $\phi$ kelsen er liten, men den fokuserer på en klinisk relevant problemstilling.

I en oppfølgingsstudie av 135 pasienter fra en spesialklinikk for pasienter med ASD fant man at 15 utviklet sikre affektive lidelser. Av disse 15 hadde én gjort gjentatte selvmordsfors $\varnothing \mathrm{k}$, og én hadde snakket om å ta livet av seg (Hutton et al., 2008).

I boken "Mental health aspects of autism and Asperger syndrome" skriver Ghaziuddin (2005) at suicidfors $\varnothing \mathrm{k}$ ikke er uvanlig, og at gjennomført suicid forekommer ved AS.

Boken "The Complete Guide to Asperger's syndrome" omtaler at unge med AS kan utvikle reaktive depresjoner med suicidtanker og - planer (Attwood, 2007). Attwood beskriver "depressive anfall" (depressive attacks) hvor personen impulsivt kan gjøre dramatiske selvmordsfors $\varnothing \mathrm{k}$. Slike "anfall” er kortvarige, og verken før eller etter anfallet viser personen tegn på depressiv problematikk.

I "A Guide to Asperger syndrome" beskrives selvmordstanker som meget vanlig hos unge og unge voksne med AS, og det beskrives en klar overhyppighet av giennomførte selvmord (Gillberg, 2002). Forfatteren anfører at triggere for selvmordsfors $\varnothing \mathrm{k}$ især er mobbing og følelsen av ikke å mestre sosiale krav. Han skriver at gutter med AS ikke sjeldent bruker voldsomme suicidmetoder som hengning, skyting eller å hoppe foran et tog.

\section{Kliniske erfaringer}

Basert på mange års arbeid i ungdomspsykiatrien og voksenpsykiatrien, er det mitt inntrykk at selvmordstanker og selv- mordsytringer forekommer sjeldnere hos unge med AS enn ved mange andre psykiske lidelser. Særlig er det mindre suicidal atferd knyttet til skam- og skyldtematikk. Vanskene med innlevelse og med å ta andres perspektiv "beskytter" sannsynligvis til en viss grad mot skyldog skamreaksjoner som ellers kan være sterke følelser hos unge.

Da forskningen på suicidal atferd ved AS er begrenset, har jeg forelagt problemstillingen for tre internasjonalt ledende autismeforskere. Den canadiske autismeforskeren Peter Szatmari skriver: "Mitt kliniske inntrykk er at selumordsforsøk er ganske sjeldent $i$ AS-populasjonen. Trusler kan forekomme hyppigere, men det kan være fordi AS-ungdommer som blir sinte eller stressede ... impulsivt kan slenge ut ting de ikke mener." (personlig meddelelse, 2009).

Digby Tantam, en engelsk autismeforsker, tror at "... selumord er mindre vanlig hos mennesker med AS .... Min forklaring på den lave forekomsten av selvskading og muligvis også suicid, er at det er en sterk kulturell påvirkning på forekomsten av begge. Hvis du er utenfor det sosiale nettverket, har disse fenomenene mindre påvirkningskraft, og man lærer ikke "ved osmose" metodene man kan bruke for å skade eller ta livet av seg." (personlig meddelelse, 2009).

"Det er mitt kliniske inntrykk at suicidtanker forekommer hyppigere hos unge med AS enn $i$ befolkningen generelt", skriver den profilerte AS-spesialisten Tony Attwood, "men jeg er ikke sikker på hvordan hyppigheten er $i$ forhold til andre psykiske lidelser. Det kan være en forskjell på å ha selumordstanker og reelle selumordsoverveielser. Dessverre har jeg flere pasienter som har tatt livet av seg. Det kan forekomme det jeg kaller et "selumordsanfall" (suicide attack)", en intens og dramatisk overreaksjon på en feil eller på en kritikk. Følelsen er svært kortvarig, men kan få katastrofale følger. Noen timer senere er personen gjerne glad og rolig."

\section{Diskusjon}

Forekomst av selvmordsatferd ved AS

Som det fremgår av ovenstående, er ledende fagfolk langt fra enige om hvor vanlig suicidal atferd er hos personer med AS. Unders $\varnothing$ kelser som tyder på høye forekomster, er typisk basert på små og kliniske populasjoner. Selvmordsfors $\varnothing \mathrm{k}$ og selvmordsutsagn er vanlige årsaker til henvisning til psykiatrien, og det er sannsynlig at man vil finne høye forekomster i kliniske populasjoner. Fitzgerald beregnet en 16-dobling av suicidforekomst basert på Wolff og McGuires undersøkelser av pasienter med "schizoid personlighet". Forfatterne anførte imidlertid at kun 3 av de 32 mennene og ingen av de 17 kvinnene i unders $\varnothing$ kelsen hadde hatt autismesymptomer i barndommen. Dette tyder på at få av disse pasientene kan ha hatt AS.

Det er ikke mulig ut fra eksisterende forskning å si noe sikkert om suicidforekomst eller forekomst av suicidal atferd ved AS. Det er i år 20 år siden diagnosen AS kom med i ICD-klassifikasjonen. I forhold til selvmordsforskning er et tidsperspektiv på under 20 år beskjedent. Det bør påbegynnes systematisk forskning på sammenhengen mellom AS/ASD og suicidal atferd.

\section{Forebygging av suicid ved AS}

Selvmordsfors $\varnothing \mathrm{k}$ og selvmord forekommer hos mennesker med AS. Et selvmordsfors $\varnothing \mathrm{k}$ kan forstås som et uttrykk for at noe har sviktet i håndteringen av de utfordringene som knytter seg til det å vokse opp med AS. Forebygging blir derfor primært et spørsmål om å sørge for kunnskap om AS i alle deler av hjelpeapparatet.

Årene før diagnostisering representerer ofte vanskelige år for mennesker med AS. Problematisk atferd forstås som "viljestyrt", og ofte vil både voksne og jevnaldrende møte AS-barnet på uheldige måter. I ungdomsårene ses ofte utst $\varnothing$ tning og mobbing som kan føre til depresjonsutvikling og $\varnothing \mathrm{kt}$ selvmordsrisiko. Tidlig diagnostisering kan sannsynligvis forebygge selvmordsatferd.

For barn med AS er det avgjørende at tilrettelegging og hjelpetiltak i skolesystemet fungerer. Mange har spesifikke lærevansker som det er viktig at fanges opp. Ofte utnyttes ikke de mulighetene som barnets spesielle evner representerer. Høyt kunnskapsnivå i PP-tjenesten, barne- og ungdomspsykiatrien og i skolesystemet generelt er avgjørende for at barn og unge med AS ikke skal oppleve un $\varnothing$ dvendige nederlag. 


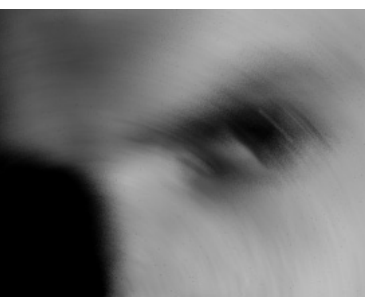

For de fleste med AS vil overgangen til studier by på problemer. Kravene til å organisere egen hverdag og til å ta ansvar for egen læring kan være vanskelige å honorere for den som har vansker med planlegging, oversikt og fleksibilitet. $\AA$ flytte hjemmefra innebærer et tap av praktisk st $\varnothing$ tte og tilrettelegging. Sosialog helsetjenester for studenter på høyere læreanstalter må ha kunnskap om AS.

De fleste med AS får vansker på arbeidsmarkedet, og altfor mange uføretrygdes i ung alder. I USA har man gjennom målrettet og kunnskapsbasert habilitering vist at mennesker med AS kan fungere godt $i$ arbeidslivet (Van Bourgondien et al., 2003). I Danmark er det etablert et firma som har hatt stor suksess med utelukkende å ansette mennesker med autismespektrumforstyrrelser (www.specialisterne.dk). God integrering forebygger med stor sannsynlighet suicidal atferd.

Tilrettelegging, pedagogikk og andre ikke-medikamentelle strategier er de viktigste metodene i håndteringen av de vanskene mennesker med AS møter (Steindal \& Martinsen, 2003). Dette er det svært viktig å vite som fagut $\varnothing$ ver i psykiatrien. For eksempel vil man ofte kunne avhjelpe en paranoid dekompensering gjennom å identifisere og endre stressmomenter som har utløst symptomene. $\AA$ ty til medikamentell behandling uten først å ha gjort et grundig "forståelsesarbeid" i forhold til de aktuelle vanskene, er symptombehandling som kan stå i veien for viktige endringer i tilrettelegging og pedagogikk.

Diagnostisering av komorbide psykiske lidelser er en vesentlig del av dette "forståelsesarbeidet”. Medikamentell behandling kan for noen være nødvendig. For AS-barnet med en hyperkinetisk lidelse kan medikamentell behandling forebygge skolevansker, atferdsvansker og utst $\varnothing$ tning. For den unge med AS og komorbid depresjons- eller angstlidelse kan det være avgjørende at den psykiske lidelsen behandles medikamentelt (Towbin, 2003).

Diagnostisk overskygging medfører risiko for undervurdering av psykopatologi ved AS. Manglende kunnskap om utviklingsforstyrrelser kan på den andre siden føre til at AS feildiagnostiseres og dermed feilbehandles (Hjort, 2005).

\section{Er det spesielle momenter som $b \phi r$ vektlegges ved vurdering av selv- mordsfare ved AS?}

Mekanismene i "den suicidale prosessen" kan være atypiske hos personer med AS.

Det er viktig at omgivelsene er oppmerksomme på mulige depresjonssymptomer. Mobbing og utst $\varnothing$ tning er risikomomenter. Spesielt endring av atferd b $\varnothing \mathrm{r}$ føre til skjerpet oppmerksomhet.

Noen med AS kan fra barnealder ha en spesiell interesse for temaet $\mathrm{d} \varnothing \mathrm{d}$ (Gillberg, 2002). Forståelig nok kan dette uroe voksne, men en slik opptatthet behøver ikke å tyde på selvmordsfare. Det er forskjell på om interessen har karakter av en "særinteresse", eller om temaet kommer opp i forbindelse med følelsesmessige belastninger.

Det er kjent at barn med AS stereotypt kan henge seg opp i å si eller gjøre ting, eksempelvis fremsette selvmordstrusler, som skaper reaksjoner hos personer i omgivelsene. Det har vært spekulert i om dette er en måte å håndtere vanskene med sosial fortolkning (Steindal, 1994). I sjeldne tilfelle kan unge med AS ha risikoatferd. En ung mann hadde som "hobby" å sykle nedover svingete veier og kjøre så tett på møtende biler han klarte. Sannsynligvis hang atferden både sammen med en redusert evne til å forstå mulige konsekvenser og med at han skapte engstelse hos folk rundt ham.

Mange med AS forstyrres av forhold som andre oppfatter som bagatellmessige. Frustrasjon kan føre til utagering eller selvskading. Spesielt bør man være oppmerksom på "det impulsive suicidforsøket" som kan utløses av tilsynelatende bagatellmessige frustrasjoner. Slike selvmordsfors $\varnothing \mathrm{k}$ er ikke uttrykk for en langvarig fortvilelse, og de forstås kanskje best som uhensiktsmessig atferd som personen trenger hjelp til å endre.

For mennesker med AS vil tydelige avvik ikke gi samme risiko for sjikanering som mer utydelige avvik (Shtayermman, 2007). Dette tilsynelatende paradokset gir utfordringer for hjelpere som jobber med å "lære" mennesker med AS normal atferd.

Wing skriver om en ung mann med AS som både hadde fors $\varnothing \mathrm{kt}$ å henge seg og å drukne seg uten å lykkes. Han forklarte at han "ikke var særlig praktisk" (Wing, 1981). Velges en lite effektiv metode til et suicidfors $\varnothing \mathrm{k}$, må dette ikke isolert sett tas til inntekt for at den suicidale intensjon har vært lav.

Unge og voksne med AS kan utvikle misbruk av alkohol eller illegale rusmidler. Rusmisbruk er forbundet med $\varnothing \mathrm{kt}$ risiko for selvmordshandlinger og fører også til $\varnothing$ kte tilpasningsvansker. A forebygge og behandle rusmisbruk er derfor viktige suicidforebyggende tiltak.

Svært mange mennesker med AS er engstelige for sykdom, blod og for sykehusvesen generelt. Slik engstelse kan i noen tilfeller fungere "beskyttende" mot selvskadende atferd.

\section{Hvordan forholde seg til suicidal atferd hos mennesker med AS?}

Ved mistanke om suicidalitet hos mennesker med AS må man, som hos alle andre, ta mistanken på alvor og begynne et grundig arbeid for å forstå personen det gjelder og den situasjonen hun eller han befinner seg i. Særlig viktig er det å gjøre en systematisk depresjonsvurdering. AS-pasienten kan som regel selv bidra i et slikt "forståelsesarbeid", og det er viktig at spørsmål om selvmordstanker formuleres konkret og nøytralt. De fleste med AS har begrensninger i selvforståelsen og evnen til å formidle følelser, og derfor er det viktig å opps $\varnothing$ ke informasjon hos familie og andre nærstående personer.

Attwood (2007) skriver om en tenåring med AS som til stadighet sa at han ville ta livet av seg. Han ble bedt om, på et "følelsestermometer" med en skala fra 1 til 10, å angi hvor frustrert han måtte være for å ytre selvmordstrusler. Svaret var 2 (10 representerte maksimal frustrasjon). Guttens ytringer ble forstått som et uttrykk for hans begrensede språk for skuffelser og tristhet. Denne kasuistikken illustrerer at selvmordsytringer ikke alltid er ensbetydende med reell selvmordsfare. Dette er ikke spesielt for AS, men ved autismespektrumforstyrrelser kan fortolkningen av ytringene ofte by på st $\varnothing$ rre problemer enn ellers. Attwoods tilnærming er et godt eksempel på hvordan konkrete spørsmål kan bidra i vurderingen av suicidrisiko.

Asperger (1944) beskriver at en tilnærming med affektivt nedtonete, nøkternt 
formidlete råd og anvisninger ofte er nyttig i håndteringen av personer med AS.

Tydelige og konkret formulerte råd om ikke å gjøre selvmordsfors $\varnothing \mathrm{k}$ kan fungere godt ved AS (Gillberg, 2002). A fortelle at mislykkede fors $\varnothing \mathrm{k}$ kan føre til hjerneskade kan ifølge Gillberg også virke forebyggende.

Gillberg anfører at "intensive, outspoken group therapy" kan føre til forvirringstilstander og suicidfors $\varnothing \mathrm{k}$ hos personer med AS. Gruppepsykoterapi er imidlertid sjelden en aktuell behandlingsform for mennesker med AS. Gruppebasert sosial trening, hvor både metodene og målsetningene er tilpasset de grunnleggende problemstillingene mennesker med AS sliter med, har derimot vist seg nyttige (Tse et al., 2007).

Depresjonssymptomer kan være atypiske ved AS, men som regel kan depresjon likevel diagnostiseres når man sammenligner symptombildet med personens normale fungering. Ved depressive symptomer må man aktivt spørre både pasienten og nærstående personer om mulige selvmordstanker og - planer.

Både ved alvorlige depressive tilstander og ved psykotiske symptomer kan innleggelse bli nødvendig. Antidepressiva vil ofte være aktuelt, men det bør utvises forsiktighet med bruk av nevroleptika (Hjort, 2005).

\section{Konklusjon}

Det finnes lite forskningsbasert kunnskap om suicidalitet ved AS. Inntil slik kunnskap foreligger, må man forholde seg til erfarne klinikeres praksisbaserte kunnskap. Det er betydelig uenighet om hyppigheten av suicidal atferd, men st $\varnothing$ rre enighet om mekanismene bak suicidalitet ved AS. Den sannsynligvis viktigste forebyggende innsatsen består i å sørge for god kunnskap om AS på alle nivåer fra barnehager og skolesystem til sosial- og helsevesen. Psykoedukative tiltak for pår $\varnothing \mathbf{r}$ ende og andre nærstående personer er også viktige.

Ved mistanke om suicidrisiko må fagpersoner med kunnskap om AS spesielt og om suicidal atferd generelt konsulteres.

Det er å håpe at forskning om suicidalitet ved AS/ASD vil bli prioritert i årene som kommer. Forskningen bør både fokusere på epidemiologi og på mer praksis- nære spørsmål som risikofaktorer og forebygging samt på hvordan man skal vurdere suicidalitet og hvordan forholde seg til manifest suicidal atferd ved AS.

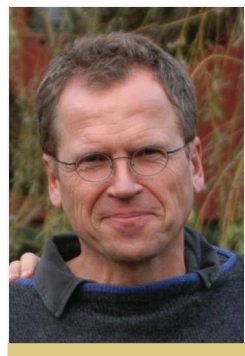

\section{Christian Hjort er lege} og spesialist i psykiatri og i barne- og ungdomspsykiatri. Han jobber som overlege på Studenthelsetjenesten i Oslo.

\section{Referanser}

Asperger, H. (1944). "Autistic psychopathy” in childhood. I "Autism and Asperger syndrome" U Frith. (red.). Cambridge: Cambridge University Press, 1991.

Attwood, T. (2007). The Complete Guide to Asperger's syndrome. London: Jessica Kinglsey.

Baron-Cohen, S., Mortimore, C., Moriarty. J., Izaguirre, J. \& Robertson, M. (1999). The prevalence of Gilles de la Tourette's Syndrome in children and adolescents with autism. J Child Psychol Psychiat, 40(2), 213-8.

Fitzgerald, M. (2002). Misdiagnosis of Asperger syndrome as anankastic personality disorder. Autism, 6(4), 435.

Fitzgerald, M. (2007). Suicide and Asperger's syndrome. Crisis, 28(1), 1-3.

Ghaziuddin, M., Ghaziuddin, N. \& Greden, J. (2002). Depression in Persons with Autism: Implications for Research and Clinical Care. J. Aut. Dev. Disord., 32(4), 299-306.

Ghaziuddin, M. (2005). Mental health aspects of autism and Asperger syndrome. London: Jessica Kinglsey.

Gillberg, C. (2002). A Guide to Asperger syndrome. Cambridge: Cambridge University Press.

Goldstein, S.\& Schwebach, A. J. (2004). The comorbidity of Pervasive Developmental Disorder and Attention Deficit Hyperactivity Disorder: results of a retrospective chart review. J Aut Dev Dis, 34(3), 329-39

Hardan, A. \& Sahl, R. (1999). Suicidal behavior in children and adolescents with developmental disorders. Research in Developmental Disabilities, 20(4), 287-96

Hjort, C. (1994). Asperger's syndrom. En ny diagnose i den internationale sygdomsklassifikation. Ugeskrift for Læger, 156(18), 2729-34.

Hjort, C. (2005). Asperger syndrom og psykiske lidelser. Masteroppgave ved Institutt for helseledelse og helse $\varnothing$ konomi, Universitetet i Oslo.

Howlin, P. (2000). Outcome in adult life for more able individuals with autism and Asperger syndrome. Autism, 4(1), 63-83.

Hutton, J., Goode, S., Murphy, M., Le Couteur, A. $\&$ Rutter M. (2008). New-onset psychiatric disorders in individuals with autism. Autism, 12(4), 373-90. Jopp, D. A. \& Keys, C. B. (200l). Diagnostic Overshadowing Reviewed and Reconsidered. Am J Mental Retardation, 106(6), 416-33.
Kadesjø, B., Gillberg, C. (2000). Tourette's Disorder: epidemiology and comorbidity in primary school children. J Am Acad Child Adolesc Psychiatry, 39(5), 548-55.

Kobayashi, R. \& Murata, T. (1998). Behavioral characteristics of 187 young adults with autism. Psychiatry and Clinical Neurosciences, 52(4), 383-90.

Lainhhart, J. E. (1999). Psychiatric problems in individuals with autism, their parants and siblings. International Review of Psychiatry, 11, 278-98.

Larsen, F. W. \& Mouridsen, M. F. (1997). The outcome in children with childhood autism and Asperger syndrome originally diagnosed as psychotic. A 30-year follow-up study of subjects hospitalized as children. European Child \& Adolescent Psychiatry, 6, 181-90.

Pelletier, G. (1998). Borderline personality disorder vs. Asperger's disorder. J Am Acad Child Adolesc Psychiatry, 37 (11), 1128.

Shtayermman, O. (2007). Peer victimization in adolescents and young adults diagnosed with Asperger's syndrome: A link to depressive symptomatology, anxiety symptomatology and suicidal ideation. Issues in Comprehensive Pediatric Nursing, 30, 87-107.

Stahlberg, O., Soderstrom, H., Rastam, M. \& Gillberg, C. (2004). Bipolar disorder, schizophrenia, and other psychotic disorders in adults with childhood onset $\mathrm{AD} / \mathrm{HD}$ and/or autism spectrum disorders. Journal of Neural transmission, 111, 891-902.

Steindal, K. (1994). Aspergers syndrom. Hvordan forstå og hjelpe personer med Aspergers syndrom og høytfungerende personer med autisme. Landsforeningen for autister.

Steindal, K. \& Martinsen, H. (2003). Hverdag og hverdagslig planlegging $i$ enestående liv - utfordringer knyttet til Aspergers syndrom. I "Habiliteringsarbeid i et individuelt og samfunnsmessig perspektiv", Unipub forlag.

Stewart, M. E. (2006). Presentation of depression in autism and Asperger syndrome. A review. Autism, 10(1), 103-16.

Sturm, H., Fernell, E., Gillberg, C. (2004). Autism spectrum disorders in children with normal intellectual levels: associated impairments and subgroups. Dev Med and Child Neur, 46(4) 44-7.

Tantam, D. (2003). The challenge of adolescents and adults with Asperger syndrome. Child Adolesc Psychiatric Clin N Am, 12, 143-63.

Towbin, K. E. (2003). Strategies for pharmacological treatment of high functioning autism and Asperger syndrome. Child Adolesc Psychiatric Clin N Am, 12, 23-45.

Tse, J., Strulovitch, J., Tagalakis, V. Fombonne, E. (2007). Social skills training for adolescents with Asperger syndrome and high-functioning autism. J Autism Dev Disord, 37(10), 1960-8.

Van Bourgondien, M. E., Reichle, N. C., Schopler, E. (2003). Effects of a model treatment approach on adults with autism. J Autism Dev Disord., 33(2), 131-40.

Volkmar, F. R. \& Cohen D. J. (1991). Comorbid Association of Autism and Schizophrenia. Am J Psychiatry, 148(12), 1705-7.

Wing, L. (1981). Asperger's syndrome: a clinical account. Psychological Medicine, 11, 115-29.

Wolff, S. \& McGuire, J. (1995). Schizoid Personality in Girls: A Follow-Up Study - What are the Links with Asperger's Syndrome. J. Child Pschol. Psychiat., 36(5), 793-817. 